\title{
The Investigation of the Oxidative Stress-Related Parameters in High Doses Methotrexate-Induced Albino Wistar Rats
}

\section{Saka $\mathrm{S}^{1,2^{*}}$ and Aouacheri $\mathrm{O}^{1}$}

${ }^{1}$ Department of Biochemistry, Badji Mokhtar University, Annaba, Algeria

${ }^{2}$ Department of Biology, Badji Mokhtar University, Annaba, Algeria

\begin{abstract}
Methotrexate (MTX) is used as a chemotherapeutic agent used to treat many cancer types. Methotrexate was known for its toxic effects involving most of the body organs including liver, kidney, intestines and blood components. The aim of the present study was to investigate the antioxidant status during oxidative stress via biological, biochemical and haematological parameters in rats subjected to oral high-doses of methotrexate. Forty male albino rats were equally divided at random into four groups; the first group was the control and the other three groups were treated per os for 7 days with three different doses (1/10, 2/10 and 3/10 of an LD50) of MTX respectively. The methotrexate-treatment of rats caused critical changes in the biological, biochemical and haematological markers. Mainly, an increase in the organo-somatic indexes (organo-megaly), a decrease in urine output value (nephotoxicity) and also a perturbation in most blood components (haematoxicity) were appeared. In addition, MTX has a prooxidant effect, which was indicated by a decrease of the antioxidant parameters in different studied tissues. In view of these results, a close relationship was shown between the increasing MTX-doses and the oxidative stress intensity, characterized by perturbations in biochemical and haematological markers.
\end{abstract}

Keywords: Methotrexate; Toxicity; Oxidative stress; Glutathione metabolizing system; Rats

\section{Introduction}

Methotrexate (MTX, 4-amino-N10-methyl folic acid) was first developed in the 1940s as a specific antagonist of folic acid [1,2]. This drug inhibits the proliferation of malignant cells primarily by inhibiting the de novo synthesis of purines and pyrimidines. Because the administration of high doses of reduced folic acid or even folic acid itself can reverse the antiproliferative effects of methotrexate, it is clear that methotrexate does act as an antifolate agent [3]. Interestingly although not originally designed as such methotrexate appears to be a pro-drug, i.e., a compound that is converted to the active agent after uptake. It is taken up by cells via the reduced folate carrier and then it is converted within the cells to polyglutamates [4].

Methotrexate is a folic acid antagonist, widely used as a chemotherapeutic agent in the treatment of various cancerous stages (leukaemia, lymphoma, osteosarcoma, head and neck tumours, lung cancer, breast cancer, etc.) and in the treatment of various inflammatory diseases [5,6]. It is also used for the treatment of multiple sclerosis, dermatomyositis, sarcoidosis, psoriasis, and rheumatoid arthritis, disorders causing inflammation. Its side effects include hypersensitivity pneumonia, central and peripheral nervous system toxicity, liver and gastrointestinal system dysfunctions and hematologic failure [7].

After absorption, $10 \%$ of methotrexate is converted to 7-hydroxy methotrexate in the liver. Both methotrexate and its metabolite (7-hydroxy methotrexate) are primarily excreted by the kidneys although a small portion is also excreted in the bile. Methotrexate is a drug with low-to-medium protein binding and high tissue distribution. It accumulates in the extra-vascular pool, and dialysis only results in a transient decrease in drug concentration. The half-life of methotrexate in the serum is in the range of 6-8 $\mathrm{h}$ after administration of the drug, and methotrexate is undetectable in the serum by $24 \mathrm{~h}$. Once takenup by cells, a portion of methotrexate and 7-hydroxy methotrexate is metabolized to polyglutamate derivatives. Methotrexate polyglutamates (MTX-Glu) are stored in the tissues, including liver and erythrocytes, for long periods. The concentration of MTX-Glu in erythrocytes roughly correlates with the therapeutic efficacy of the drug [8].

MTX exerts its primary toxic effects against the rapidly replicating cells of the bone marrow and gastrointestinal epithelium producing leucopoenia and thrombocytopenia. Both low and high-dose therapy can cause hepatotoxicity. Methotrexate at very low dosage affects the liver and causes changes in histology of liver. Other frequently reported adverse toxic effects are malaise, nausea, vomiting, diarrhoea, headache, mild alopecia and fever. Low dose therapy produces a different type of hepatotoxicity which includes cirrhosis. Long term administration of the same causes anaemia. Kidney damage is a frequent complication of high-dose therapy. However, the use of high-dose methotrexate (as in leukaemia) or prolonged use may result in hepatotoxicity that may lead to progressive fibrosis and cirrhosis. Methotrexate seems to be hepatotoxic, nephrotoxic and toxic to respiratory and reproductive system at very low doses for continuous therapy [9].

On the other hand, substantial evidence supports the concept that MTX was mutagenic and carcinogenic in animals, and the efficacy of this compound is often limited by its severe hepatotoxicity [10]. Toxic side effects of methotrexate have been demonstrated in various animals including rat, mice, rabbit and dog. Clinically, hepatotoxicity, which occurs in long-term use of methotrexate, remains one of the significant restrictions on its use in the doses desired. The inhibition of tetrahydrofolate formation is responsible for both the therapeutic and toxic effects of methotrexate. Although these deleterious toxic

${ }^{*}$ Corresponding author: Saka S, Faculty of Sciences, Applied Biochemistry and Microbiology Laboratory, Department of Biochemistry, Badji Mokhtar University, Annaba, Algeria, Tel: +213 38871061; E-mail: sakasadz@yahoo.fr

Received March 21, 2017; Accepted March 27, 2017; Published March 31, 2017

Citation: Saka S, Aouacheri O (2017) The Investigation of the Oxidative StressRelated Parameters in High Doses Methotrexate-Induced Albino Wistar Rats. J Bioequiv Availab 9: 372-376. doi: 10.4172/jbb.1000327

Copyright: ( 2017 Saka S, et al. This is an open-access article distributed under the terms of the Creative Commons Attribution License, which permits unrestricted use, distribution, and reproduction in any medium, provided the original author and source are credited. 
Citation: Saka S, Aouacheri O (2017) The Investigation of the Oxidative Stress-Related Parameters in High Doses Methotrexate-Induced Albino Wistar Rats. J Bioequiv Availab 9: 372-376. doi: 10.4172/jbb.1000327

effects of methotrexate can theoretically be reduced or prevented with the addition of folic acid to the treatment. On the contrary, there are studies showing that with the addition of folic acid, the therapeutic effectiveness of methotrexate decreases [5].

Methotrexate is a folic acid dihydrofolate reductase inhibitor, affects primarily the tissues that are growing most rapidly. Toxicity studies with methotrexate highlight the role of oxidative stress in causing toxicity on the liver, kidney, heart and other organs [2]. The most serious side effect of MTX therapy is the hepatic toxicity [11], illustrated by elevated liver enzymes [9]. It is reported that mild hepatitis, cholestasis, fatty changes, fibrosis and cirrhosis, in patients receiving MTX for malignant disorders [2]. The underlying mechanism of hepatotoxicity caused by MTXtreatment remains unclear. However, it has been reported that MTX causes oxidative stress in liver tissue. Although 7-hydroxy metabolite is the major pathway of MTX metabolism, the latter is metabolized and stored in hepatocytes in the polyglutamated form. The presence of higher levels of polyglutamates causes a longer intracellular presence of the drug and this has been suggested as a mechanism for hepatotoxicity. Moreover, MTX inhibits dihydrofolate reductase; it indirectly affects the synthesis of thymidylate, thereby suppressing DNA synthesis [12].

MTX has been shown to lead to a reduction in methionine synthesis, antioxidant enzymes such as catalase, Glutathione Peroxidase (GPx), Superoxide Dismutase (SOD) and a decrease of S-Adenosyl Methionine (SAM) in cerebrospinal fluid of patients on MTX treatment. Due to its antioxidant effects, a deficiency of SAM caused by MTX may be a reason for increased Reactive Oxygen Species (ROS). Effects of MTX are partly due to its direct toxicity by increasing ROS production. Altered balance between ROS production and antioxidant defences leads to the oxidative stress and could lead to various pathological states. The mechanisms of MTX hepatotoxicity could be related to the cellular pathway of the drug [6]. Additionally, it was demonstrated that the cytosolic NADP-dependent dehydrogenases and NADP malic enzyme are inhibited by MTX, suggesting that the drug could decrease the availability of NADPH in cells [12]. Mechanism of methotrexate induced hepatotoxicity includes oxidative stress which increase the generation of reactive oxygen (ROS) and nitrogen species, inhibits cytosolic NADP-dependent dehydrogenase and NADP malic enzyme, which reduce the levels of glutathione, superoxide dismutase, catalase and ultimately reducing the effectivity of the antioxidant defence system protecting the cell against ROS [6]. Under normal conditions, NADPH is used by Glutathione Reductase (GR) to maintain the reduced state of cellular Glutathione (GSH), an important cytosolic antioxidant, which protects against ROS. Thus, the significant reduction in glutathione levels induced by MTX leads to reduction in the level of the antioxidant enzyme defence system, sensitizing the cells to ROS [12]. Effects of MTX are partly due to its direct toxicity by increasing ROS production. Altered balance between ROS production and antioxidant defences leads to the oxidative stress and could provoke various pathological conditions [6]. Moreover, Abd-Allah and Sharaf El-Din [13] confirmed that the MTX induced serious damage is characterized by marked inflammation and increased production of reactive oxygen species and therefore increased oxidative stress. Toxicity studies with methotrexate highlight the role of oxidative stress in causing toxicity on the liver and other organs. Levels of both enzymatic and non-enzymatic anti-oxidants are inhibited and the levels of oxidants increase in the liver, kidney, and gut tissues of laboratory animals given methotrexate. It is therefore thought that antioxidant therapy may be useful in preventing or reducing hepatotoxicity due to methotrexate. Although these deleterious toxic effects of methotrexate can theoretically be reduced or prevented with the addition of folic acid to the treatment, there is yet no consensus on the subject [5]. On the contrary, there are studies showing that with the addition of folic acid, the therapeutic effectiveness of methotrexate decreases. This indicates that the mechanism of action of methotrexate hepatotoxicity has not yet been fully explained [14]. In addition, oxidative stress is known to induce apoptosis by damaging DNA, oxidizing membrane lipids, and/ or directly activating the expression of the genes/proteins responsible for apoptosis [13].

The aim of this study is to investigate the possible estimation of potential hepatic, renal and intestinal toxicity in methotrexate treated rats via the dosage of glutathione metabolizing system.

\section{Materials and Methods}

\section{Experimental animals}

Forty male rats (Albino Wistar) were provided from Algiers Pasteur Institute, at the age of 10 weeks, with an average live weight of $200 \pm 10$ g. They were housed in group cages for 2 weeks to acclimatize under ambient temperature $\left(21 \pm 2^{\circ} \mathrm{C}\right)$ and standard daily light. They were given a nutritionally adequate specified rat's diet and water ad libitum throughout the experimental period. The animals were then randomly divided at random into 4 groups of 10 animals each and housed individually in metabolism cages. The experimental procedures were carried out according to the National Institute of Health Guidelines for Animal Care and approved by the Ethics Committee of our Institution.

\section{Preparation of methotrexate solution}

Methotrexate tablet (Pfizer AG, Switzerland) is dissolved in mineral water, and induced by oral gavage. The volume of each dose was adjusted to deliver $3.17,6.34$ and $9.51 \mathrm{mg} / \mathrm{kg}$ of body weight corresponding to $1 / 10,2 / 10$ and $3 / 10$ of an LD50 of MTX solution. Knowing that, the orally LD50 is $317 \mathrm{mg} / \mathrm{kg}$ in rats [15].

\section{Animal treatment}

Animals in each experimental group were treated for seven days with oral gavage (per os) using a gastric tube of three different doses $1 / 10,2 / 10$ and $3 / 10$ of an LD50 of MTX solution. Control animals were treated per os with mineral water only. Following seven days, treatment period, animals were maintained in individual cages. Water consumption, food intake and urine output were measured daily throughout the experimental period. At the end of treatment period, i.e., on the eighth day animals were sacrificed by decapitation and blood samples were collected in EDTA tubes for the Complete Blood Count (CBC) [16]. Many organs were rapidly removed, washed with $0.1 \mathrm{M}$ phosphate buffered saline ( $\mathrm{pH} 7.4$ ), weighed and stored at $-20^{\circ} \mathrm{C}$ for the determination of organo-somatic indexes and glutathione metabolising parameters. The organo-somatic indexes show the weight of each organ as a percentage of body weight [17]. The reduced glutathione was determined spectrophotometrically, according to the Weckbecker and Cory method [18], the glutathione S-transferase activity was estimated by Asaoka and Takahashi method [19] and the content of total protein by the method of Bradford [20]. Data are expressed as the means \pm $\mathrm{SD}$. The significant differences in mean values among the control and treated groups were evaluated following Students T-test using Minitab software (version 13.31).

\section{Results}

\section{Physiological study}

Exposure of rats to methotrexate did not produce any overt sign 
Citation: Saka S, Aouacheri O (2017) The Investigation of the Oxidative Stress-Related Parameters in High Doses Methotrexate-Induced Albino Wistar Rats. J Bioequiv Availab 9: 372-376. doi: 10.4172/jbb.1000327

of toxicity/mortality. No significant differences were reported in water consumption or feed intake during the whole experimental period. However, the urine output decreased in all methotrexate-treated rats (Table 1). Concerning the organo-somatic indexes, Table 2 showed a significant increase in all studied organs mostly in high-doses of MTXinduced rats compared with the control.

\section{Hematological study}

Haematological study revealed that there was a highly significant decrease in erythrocyte (red blood cell) and leukocyte (white blood cell) count. While, the differential leukocyte cell counts results showed a diminution in the neutrophils and an elevation in lymphocytes' percentage, especially in high-doses of MTX-induced rats. No observed significant changes in others differential leukocyte cells (monocytes, eosinophils, basophils, myloblatocytes, mylocytes and metamyelocytes) were reported compared to control rats (Table 3).

\section{Toxicological study}

High-doses MTX intake caused an impressive oxidative stress which occurs mainly through a significant reduction in the both biomarkers of antioxidant enzyme defence system, especially GSH levels (Figure 1) and GST activities (Figure 2) in all studied organs compared to their control values.

\begin{tabular}{|c|c|c|c|c|}
\hline \multirow{2}{*}{ Parameters } & Control & \multicolumn{3}{|c|}{ Methotrexate } \\
\cline { 3 - 5 } & & $\mathbf{1 / 1 0}$ LD $_{\mathbf{5 0}}$ & $\mathbf{2 / 1 0} \mathbf{L D}_{\mathbf{5 0}}$ & $\mathbf{3 / 1 0} \mathbf{L D}_{\mathbf{5 0}}$ \\
\hline Food intake & $15.3 \pm 0.6$ & $15.7 \pm 0.3$ & $15.8 \pm 0.6$ & $14.2 \pm 0.4$ \\
\hline Water consumption & $27.9 \pm 0.5$ & $31.3 \pm 0.9$ & $30.3 \pm 0.5$ & $28.7 \pm 0.7$ \\
\hline Urine output & $6.2 \pm 1.4$ & $4.7 \pm 1.4^{*}$ & $4.5 \pm 1.6^{* *}$ & $3.2 \pm 1.3^{* *}$ \\
\hline
\end{tabular}

"p<0.05; "* $p<0.01$; " $p<0.001$. Significantly different from control

Table 1: Food intake (g/day), water consumption ( $\mathrm{ml} /$ day) and urine output ( $\mathrm{ml} / \mathrm{day}$ ) of control and methotrexate-treated rats $\left(1 / 10,2 / 10\right.$ and $3 / 10$ of an $L_{50}$ of MTX). Values are given as mean \pm standard error of 10 animals.

\begin{tabular}{|c|c|c|c|c|}
\hline Parameters (\%) & Control & \multicolumn{3}{|c|}{ Methotrexate } \\
\cline { 3 - 5 } & & $\mathbf{1 / 1 0}$ LD $_{\mathbf{5 0}}$ & $\mathbf{2 / 1 0}$ LD $_{50}$ & $\mathbf{3 / 1 0}$ LD $_{50}$ \\
\hline Hepato-somatic & $2.720 \pm 0.198$ & $2.682 \pm 0.223$ & $2.934 \pm 0.231^{*}$ & $3.630 \pm 0.332^{* *}$ \\
\hline Reno-somatic & $0.558 \pm 0.102$ & $0.554 \pm 0.222$ & $0.614 \pm 0.215$ & $0.855 \pm 0.276^{*}$ \\
\hline Spleeno-somatic & $0.259 \pm 0.054$ & $0.256 \pm 0.082$ & $0.305 \pm 0.128$ & $0.451 \pm 0.113^{*}$ \\
\hline Thymo-somatic & $0.056 \pm 0.025$ & $0.052 \pm 0.027$ & $0.063 \pm 0.028^{*}$ & $0.063 \pm 0.027^{* *}$ \\
\hline
\end{tabular}

Table 2: Organ-somatic indexes in control and methotrexate-treated rats $(1 / 10$, $2 / 10$ and $3 / 10$ of an $L_{50}$ of MTX). Values are given as mean \pm standard error of 10 animals.

\section{Discussion}

Cellular response to oxidative stress is usually related to two processes damage to cellular constituents and up-regulation of antioxidant defences. Actually, it is difficult to separate these two scenarios and the final results depend on many circumstances because

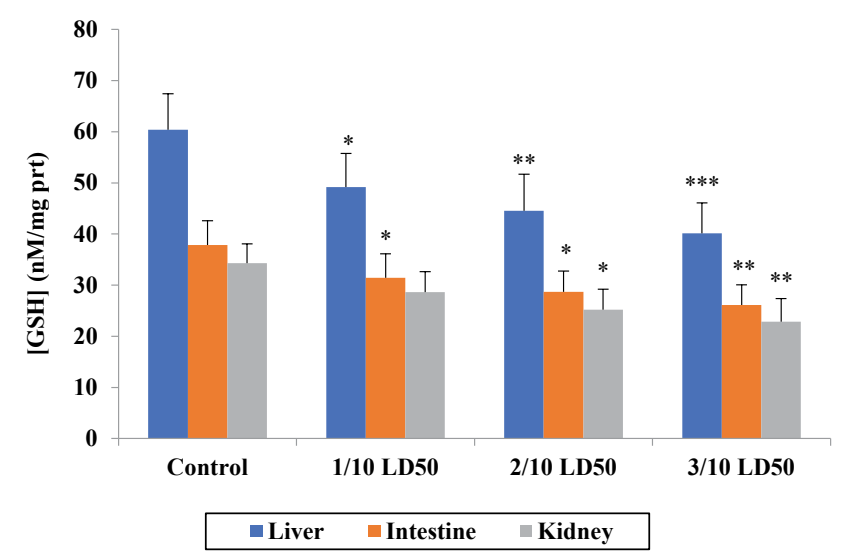

Figure 1: Glutathione level (nM/mg prt) in control and methotrexate-treated rats $\left(1 / 10,2 / 10\right.$ and $3 / 10$ of an $L_{50}$ of MTX). Values are given as mean \pm standard error of 10 animals.

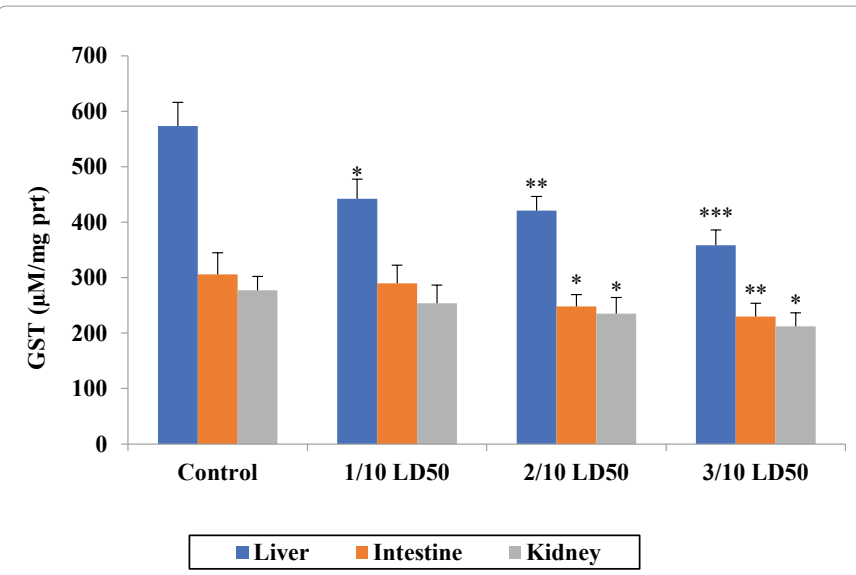

Figure 2: Glutathione S-transferase activity $(\mu \mathrm{M} / \mathrm{mg}$ prt) in control and methotrexate-treated rats $\left(1 / 10,2 / 10\right.$ and $3 / 10$ of an $L_{50}$ of MTX). Values are given as mean \pm standard error of 10 animals.

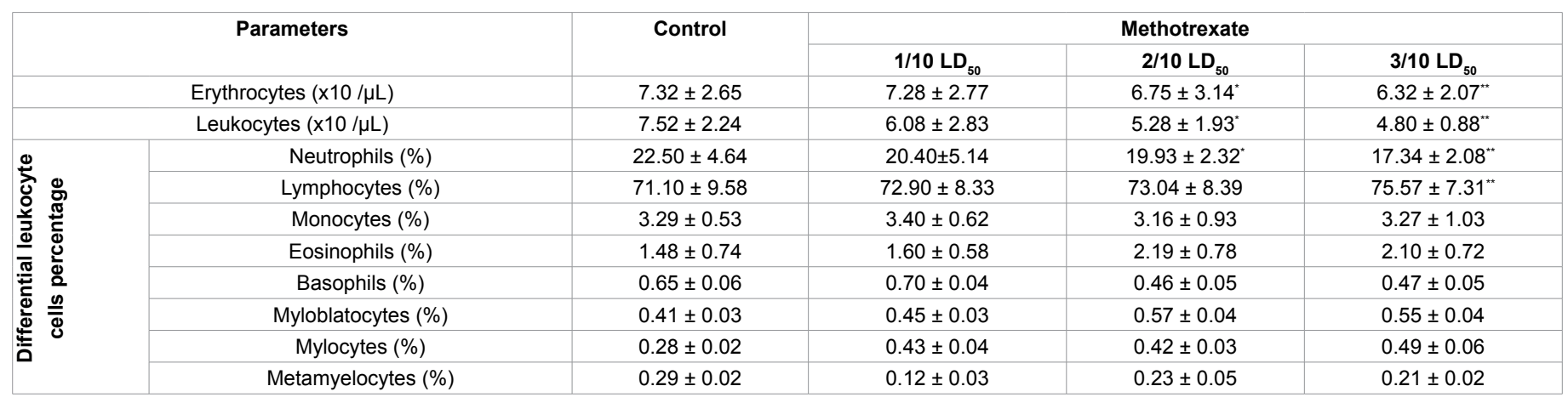

" $p<0.05 ;$; $p<0.01$. Significantly different from control

Table 3: Complete blood count (CBC) in control and methotrexate-treated rats $\left(1 / 10,2 / 10\right.$ and $3 / 10$ of an $L_{50}$ of MTX). Values are given as mean \pm standard error of 10 animals. 
Citation: Saka S, Aouacheri O (2017) The Investigation of the Oxidative Stress-Related Parameters in High Doses Methotrexate-Induced Albino Wistar Rats. J Bioequiv Availab 9: 372-376. doi: 10.4172/jbb.1000327

these processes take place simultaneously [21]. Methotrexate druginduced oxidative stress is implicated as a mechanism of toxicity in numerous tissues and organ systems, including liver, kidney, intestine, cardiovascular and nervous systems. Metabolism of a drug may generate ROS, perturbations in oxidant homeostasis and mitochondrial dysfunction which contribute to clinically relevant drug side effects. The drug could decrease the availability of NADPH in cells. This was the main reason for significant reduction in GSH level promoted by MTX and could lead to the reduction of antioxidant enzyme defence system effectiveness [22].

The animals under practice appeared healthy and did not show clinical signs of any disease and no mortality was recorded in all groups during the experiment. On the other hand, various side effects were observed in animals treated with methotrexate such as loosing of activity, weakness and fall of body hair. The MTX-treatment with different doses has not affected any significant change either in the total food intake or in the water consumption. It is suggested that the MTX do not change the taste property of food, and the animals might maintain their normal corporal weights. It means that, the diet did not change and the rats kept a normal appetite which preserved their body weight. This result is in agreement with the study of Aouacheri et al. [23]. On the contrary [9], were obtained a weight loss in MTX-treated rats, which might be a reflection of direct toxicity, reduced feed and water intake and stressogenic activity.

However, the results of urine output showed a decrease in volume excreted by all MTX-induced rats, reflecting a renal toxicity effect of this drug. This toxicity is probably due to the precipitation of MTX or its metabolites (7-hydroxy methotrexate) in the renal tubules causing obstruction and diminution of renal clearance with consequently prolongation of MTX high levels. MTX may also acts as a direct toxin on the tubular epithelium and causes vasoconstriction of the afferent arteriole [24].

Oxidative stress generated by external toxic agents may have a negative impact on many organs, including liver, kidney, spleen etc. This study shows that the higher-MTX doses can cause an increase in the organo-somatic indexes. Probably, this organo-megaly is due to the precipitation of MTX-metabolites in different studied tissues. This is consistent with Hagag et al. [25] who found the same results.

Significant decreases in erythrocyte and leukocyte counts were observed in the high-doses of MTX-treated groups. Probably, the change in erythrocyte count can be attributed to ulcers in the digestive tract resulting in gradual blood loss which supports the findings of Patel et al. [9], and eventually, leading to anaemia [26]. In the other hand, a perturbation in percentage of differential leukocyte cells was appeared in high-doses MTX-induced rats, as evidenced by the decrease in the neutrophils count was observed with an increase in lymphocytes count. Similarly, Patel et al. [9] reported the systemic effect of methotrexate at the dose rate of $0.062 \mathrm{mg}$ or $0.250 \mathrm{mg} / \mathrm{kg}$ by oral gavage in male rats. Many studies also support the view that oxidative stress plays a role in MTX-induced small intestinal damage. Reactive oxygen species trigger the accumulation of leukocytes in the tissues, and thus aggravate tissue injury indirectly through activated neutrophils [13].

Methotrexate enters the cell via active transport across the reduced folate carrier, where it is effluxed from the cell by several of the ATPBinding Cassette (ABC) transporters, especially ABCC1-5, ABCG2 and ABCB1 [2]. Levels of both enzymatic and non-enzymatic anti-oxidants are inhibited and the levels of oxidants increase in the testes, heart, liver, kidney, and gut tissues of laboratory animals given methotrexate [5]. It has further been reported that MTX-administration induces oxidative stress and significantly reduces antioxidant enzymes such as superoxide dismutase, catalase and glutathione peroxidase in liver, intestinal mucosa and spinal cord tissues of rats [27]. In liver, the conversion of MTX to its major extracellular metabolite, 7-hydroxy methotrexate, takes place where it is oxidized by a soluble enzymatic system [10]. GSH is one of the most common biologic non-enzymatic antioxidant. Its function includes removal of free radicals such as $\mathrm{H} 2 \mathrm{O} 2$ and superoxide anions, maintenance of membrane protein thiols and acting as a substrate for GPx and GR [28]. Thus, significant decrease in GSH level promoted by MTX, leads to a reduction of effectiveness of the antioxidant enzyme defence system, thereby sensitizing the cells to Reactive Oxygen Species (ROS). GSH serves as a sensitive marker of oxidative stress and it plays an important role in maintaining the integrity of the cell. Because, it involved in several detoxification reactions in the organism and it is one of the most prominent non-enzymatic antioxidants [29,30]. Many studies have shown a decrease in the GSH level in the small intestine [5] and in liver [2,30] following MTX administration. The present study showed a highly significant reduction in cellular GSH level after MTX-treatment. Recent study reported that GSH forms the first line of defence against oxidative stress, by direct interaction of its thiol group with ROS and/or it can be involved in the enzymatic detoxification reaction of ROS as a cofactor or as a coenzyme [31,32].

In liver, the conversion of MTX to its major extracellular metabolite, 7-hydroxy methotrexate, takes place where it is oxidized by a soluble enzymatic system. While inside hepatic cells, MTX is stored in a polyglutamated form [10]. Our data confirmed the concept that oxidative stress plays a role in MTX-induced tissue damage, whereas GSH reduction was accompanied by diminution in the antioxidant enzyme defence system represented as depletion in the GST activity in liver, kidney and intestine. This is in agreement with several studies demonstrated that MTX induces oxidative stress in tissues accompanied with decreased antioxidants levels. It is well documented that GST is known to detoxify carcinogenic metabolites by thiol conjugation, while GPx catalyses the reduction of $\mathrm{H}_{2} \mathrm{O}_{2}$ and hydroxyl peroxides into nontoxic products. Their decreased level was remarkable after MTX challenge and this may be one reason for high lipid peroxidation [33]. Herein, the decrease in the activities of antioxidant enzymes can be explained either with their induction during the conversion of free radicals into inactive metabolites, or secondarily with the direct inhibitory effect of MTX on enzymes activities [10]. The decrease in the activity of the free radical detoxifying enzymes, GST in studied organs of MTX-treated rats observed in the present study may be an adaptive mechanism by the cells to detoxify the MTX-metabolites in order to minimize tissue damage. The increased utilization of the reduced glutathione by this enzyme might account for the decrease in the reduced glutathione content in the small intestine.

\section{Conclusion}

It can be concluded from this study that acute exposure to methotrexate produced no appreciable changes at recommended dosage $(3.17,6.34$ and $9.51 \mathrm{mg} / \mathrm{kg}$ body weight corresponding to $1 / 10$, $2 / 10$ and 3/10 of an LD50 of MTX solution). Despite that, critical changes were appeared in the organo-somatic indexes, haematological parameters and in the level of the glutathione metabolising system. For this reason, it can be proposed the using of routine consultation of oxidative stress parameters including the glutathione metabolizing system in patients using long term MTX cure. 
Citation: Saka S, Aouacheri O (2017) The Investigation of the Oxidative Stress-Related Parameters in High Doses Methotrexate-Induced Albino Wistar Rats. J Bioequiv Availab 9: 372-376. doi: 10.4172/jbb.1000327

\section{Acknowledgements}

This work is supported by research project No.: F 332/ANDRS/2011, funded by the Ministry of Higher Education, Algeria. We would like to thank members of the Algiers Pasteur Institute for providing rats.

\section{Conflict of Interests}

The authors report no conflict of interests.

\section{References}

1. Puig L (2014) Methotrexate: new therapeutic approaches. Actas Dermosifiliogr 105: 583-589.

2. Tousson E, Atteya Z, El-Atrash A, Jeweely OI (2014) Abrogation by Ginkgo Byloba Leaf Extract on Hepatic and Renal Toxicity Induced by Methotrexate in Rats. J Cancer Res Treat 2: 44-51.

3. Chan ES, Cronstein BN (2002) Molecular action of methotrexate in inflammatory diseases. Arthritis Res 4: 266-273.

4. Chabner BA, Allegra CJ, Curt GA, Clendeninn NJ, Baram J, et al. (1985) Polyglutamation of methotrexate. Is methotrexate a prodrug? J Clin Invest 76 : 907-912.

5. Ozogul B, Kisaoglu A, Turan MI, Altuner D, Sener E, et al. (2013) The effect of mirtazapine on methotrexate-induced toxicity in rat liver. Sci Asia 39: 356-362.

6. Kumari S (2016) Methotrexate induced hepatotoxicity and its management. Inter J Sci Res 5: 1477-1481.

7. Celik FC, Gocmez M, Bozkurt I, Kaplan K, Kamasak E, et al. (2013) Neuroprotective effects of carvacrol and pomegranate against methotrexate induced toxicity in rats. Eur Rev Med Pharmacol Sci 17: 2988-2993.

8. Tian H, Cronstein BN (2007) Understanding the mechanisms of action of methotrexate: implications for the treatment of rheumatoid arthritis. Bull NYU Hosp Jt Dis. 65: 168-173.

9. Patel NN, GhodasaraDJ, Pandey S, Ghodasara PD, Khorajiya JH, et al. (2014) Subacute toxicopathological studies of methotrexate in Wistar rats. Veter World 7: 489-495.

10. Abdel Ghaffar FR, Elaimy IA, Dougdoug KA, Nassar HI (2013) Protective and modulatory effects of curcumin and L-carnitine against methotrexate-induced oxidative stress in albino rats. Res J Pharm Bio Chem Sci 4: 747-754.

11. Mardini H, Record C (2005) Detection assessment and monitoring of hepatic fibrosis: biochemistry or biopsy? Ann Clin Biochem 42: 441-447.

12. Hemeida RAM, Mohafez OM (2008) Curcumin attenuates methotraxateinduced hepatic oxidative damage in rats. J Egypt Natl Canc Inst 20: 141-148.

13. Abd-Allah OM, Sharaf El-Din Al (2013) The possible protective effect of ginger against intestinal damage induced by methotrexate in rats. Med J Cairo Univ 81: 1073-1084

14. Cetinkaya A, Bulbuloglu E, Kurutas EB, Kantarceken B (2006) N-acetylcysteine ameliorates methotrexateinduced oxidative liver damage in rats. Med Sci Monit 12: $274-278$

15. de Wyeth MC (2003) Monographie de Methotrexate: Document à l'attention des professionnels de la santé de Pfizer Canada inc. Numéro de Control 216382.

16. Zittouni R, Bernadou A, Samama M (1982) Manuel d'Hématologie ( $5^{\text {th }}$ edn.). DOIN Published, Paris.

17. Berté S, Kouamélan EP, Ouattara NI, Koné T, Goore BG, et al. (2008) Cycle de reproduction et fécondité de Distichodus rostratus (Characiformes, Distichodontidae) dans un bassin ouest africain (fleuve Bandama, Côte d'Ivoire). Tropicultura 26:104-107.

18. Weckbercker G, Cory JG (1988) Ribonucleotide reductase activity and growth of glutathione-depended mouse leukaemia L1210 cells in vitro. Cancer Lett 40: 257-264.

19. Asaoka K, Takahashi K (1983) A colorimetric assay of glutathione S-transferases using o-dinitrobenzene as a substrate. J Biochem 94: 1685-1688.
20. Bradford MM (1976) A rapid and sensitive method for the quantitation of microgram quantities of protein utilizing the principle of protein-dye binding. Anal Biochem 72: 248-254.

21. Krim M, Messaadia A, Maidi I, Aouacheri O, Saka S (2013) Protective effect of ginger against toxicity induced by chromate in rats. Ann Biol Clin (Paris) 71 : 165-173.

22. Khalil FA, EL-Kirsh AA, Kamel EA, EL-Rahmany NG (2016) Beneficial effect of propolis extract (bee glue) against Methotrexate-induced stress in liver and brain of Albino rats. Indian J Med Res Pharmac Sci 3: 24-34.

23. Aouacheri W, Saka S, Djafer R, Lefranc G (2009) Effet protecteur du diclofénac contre le stress oxydatif induit par la toxicité du paracétamol chez les rats. Ann Biol Clin 67: 619-627.

24. Gaies E, Jebabli N, Trabelsi S, Salouage I, Charfi R, et al. (2012) Methotrexate side effects: J Drug Metab Toxicol 3: 125-130.

25. Hagag AA, Elaal AMA, Elsheik A, Elzamarany EA (2013) Protective effect of nigella sativa oil against methotrexate induced hepatotoxicity in children with acute lymphoblastic leukemia. J Leuk 1: 123-129.

26. Silverman LB, Sallan SE (2003) Newly diagnosed childhood acute lymphoblastic leukemia: update on prognostic factors and treatment. Curr Opin Hematol 10: 290-296.

27. Coleshowers CL, Oguntibeju OO, Ukpong M, Truter EJ (2010) Effects of methotrexate on antioxidant enzyme status in a Rodent model. Med Tech SA 24: 5-9.

28. Naik SR, Panda VS (2007) Antioxidant and hepatoprotective effects of ginkgo biloba phytosomes in carbon tetrachloride-induced liver injury in rodents. Liver Int 27: 393-399.

29. Saka S, Aouacheri W, Abdennour C (2002) The capacity of glutathione reductase in cell protection from the toxic effect of heated oils. Biochimie 84 : 661-665.

30. Kehili N, Saka S, Aouacheri O (2017) L'effet phytoprotecteur de la nigelle (Nigella sativa) contre la toxicité induite par le cadmium chez les rats. Phytothérapie pp: 1-10.

31. Rahman K (2007) Studies on free radicals, antioxidants, and co-factors. Clin Interv Aging 2: 219-236.

32. Aouacheri O, Saka S, Krim M, Messaadia A, Maidi I (2015) The investigation of the oxidative stress-related parameters in type 2 diabetes mellitus. Can $\mathrm{J}$ Diabetes 39: 44-49.

33. Ikediobi CO, Badisa VL, Ayuk-Takem LT, Latinwo LM, West J (2004) Response of antioxidant enzymes and redox metabolites to cadmium-induced oxidative stress in CRL-1439 normal rat liver cells. Int J Mol Med 14: 87-92. 